\title{
Information at the Point of Care: Answering Clinical Questions
}

\author{
Mark Ebell, $M D, M S$
}

\section{I bave no particular talent. I am merely inquisitive.} - Albert Einstein

As physicians, we gather information from patients in the form of answers to questions, patient stories, physical examination maneuvers, and test results. We integrate that information with what we already know about our patient, his or her family and community, and information from original research, colleagues, textbooks, and other sources. We then develop a plan for evaluation and management, and implement it by communicating it to the patient and other parts of the health system. This flow of information is expensive: physicians spend more than one third of their time recording and synthesizing information. Further, communications eat up one third of a typical hospital's budget. ${ }^{1}$

Unfortunately, as we approach the 21 st century, most physicians are still using outdated tools to manage medical information. We scribble illegible notes in a chart, try to keep problem and medication lists up-to-date by hand, send letters to consultants, and telephone the laboratory for results. Questions arise at the point of care but go unanswered. Practice patterns ossify, and our textbooks grow out-of-date. Several questions arise as we consider this dilemma:

1. Just what questions do clinicians ask at the point of care?

2. What is the relationship between clinical

Submitted, revised, 29 October 1998.

From the Department of Family Practice, Michigan State University, East Lansing. Address reprint requests to Mark H. Ebell, MD, MS, Department of Family Practice, Michigan State University, B101 Clinical Center, East Lansing, MI 48824-1315. E-mail: ebell@pilot.msu.edu

This work was supported by a Robert Wood Johnson Generalist Physician Scholars award and by the American Academy of Family Physicians through the Michigan Consortium for Family Practice Research.

Dr. Ebell is programmer of the InfoRetriever software discussed in the article and receives royalty payments from its sale. $\mathrm{He}$ is also co-editor of the Fournal of Family Practice POEMs feature and co-editor of the Evidence-Based Practice newsletter, both from Dowden Publishing. questions, lifelong learning, and evidencebased medicine?

3. How can clinicians answer clinical questions at the point of care, where the answers are most likely to affect clinical practice?

4. As a primary care physician, how can I get started right now to answer my clinical questions more effectively?

This article will address all of these questions. It is important, however, first to define what is meant by a clinical question. Researchers often use the term information need to describe the broad range of questions asked by physicians during the care of patients. This term can include such patient-specific information needs as "Does this patient have rales?" "What is the serum creatinine?" and "I wonder why the patient has back pain?" asked during the data-gathering phase of the encounter. It can also include logistic and administrative questions, such as "Does this patient's insurance cover radiographs?" and "Does Dr. Hart accept patients with Medicaid?" asked during the implementation phase.

For this discussion, I will focus on generalizable questions about patient care that can potentially be answered by the medical literature. These questions are typically generated when patient data are being integrated with generalizable medical knowledge to develop a management plan. Here are some examples of such clinical questions:

1. What is the appropriate regimen for treatment of herpes zoster infection with famciclovir?

2. How effective is famciclovir at preventing postherpetic neuralgia?

3. What test, if any, should I order for an otherwise well but worried dyspeptic patient whose brother was just diagnosed with pancreatic cancer?

4. What is the best test for a jaundiced 50-yearold man who has lost 20 pounds and has a family history of pancreatic cancer?

5. Should I empirically treat a sore throat for 
streptococcal pharyngitis in this febrile child, or should I order a rapid antigen test?

6. What should I do for this 53-year-old male smoker with a cholesterol level of $260 \mathrm{mg} / \mathrm{dL}$ ?

7. Does my patient with a corneal abrasion need a patch?

8. What is the most cost-effective approach to the management of urinary tract infection?

Clinical questions are the result of critical reflection by a clinician on his or her practice. By better understanding their clinical questions generated at the point of care, family physicians can define strategies for answering these questions using relevant and valid information, and thereby improve the care of patients. I will answer some of the above clinical questions in this article as the information needs of primary care physicians at the point of care are discussed.

\section{What Questions Do Clinicians Ask at the Point of Care?}

When asked at the end of a half-day of patient care to recall how many questions they had related to patient care, physicians reported 1 question for every 4 patients. ${ }^{2}$ Direct observation of primary care physicians, however, has shown that they generate an average of 2 questions for every 3 patient encounters. ${ }^{3}$ A physician seeing 25 patients per day will generate approximately 15 questions.

These and similar studies have shown there is tremendous variety to the questions physicians ask, and these questions are often complex and patient specific. Approximately 33 percent relate to treatment, 25 percent to diagnosis, and 15 percent to pharmacotherapeutics. ${ }^{3-5}$ When questions are pursued and answered, more than one half of the answers come from textbooks and human sources, including both office partners and consultants. ${ }^{5}$ The Pbysician's Desk Reference (PDR) is perhaps the most commonly named source of answers. Electronic sources of information are rarely used. 3,4

Unfortunately, approximately two thirds of the clinical questions generated at the point of care go unanswered. ${ }^{3}$ Are these questions important? One study took the unanswered questions and gave them to medical librarians. The authors then gave the answers to the physicians who had asked them and found that approximately one half of the answers would have had a direct impact on patient care. ${ }^{6}$

Why do we not answer more of these ques- tions? Limitations include a lack of convenient access to reference materials at the point of care, the time needed to search for information, and the challenge of formulating an answerable question. ${ }^{4}$ Two characteristics that predict whether physicians will seek and find an answer to a clinical question are the urgency of the problem and their confidence that they will find an answer. ${ }^{7}$

For example, consider the physician who wants to know how to prescribe famciclovir for herpes zoster. Although he or she can be confident of finding a dosage recommendation in the PDR, this reference will not answer questions about the medication's effectiveness. Information about the number of patients this physician would have to treat to prevent a case of postherpetic neuralgia might be found in a randomized trial, but access to that information is unlikely at the point of care, and the question remains unanswered. Thus, the information a patient and physician might want so they can decide whether the medication is worth paying for and taking is not available.

A useful way to think about clinical questions is by the type of information needed. ${ }^{8}$ For example, a relatively large randomized controlled trial has shown that patching corneal abrasions only increases discomfort and healing time..$^{9} \mathrm{~A}$ family physician who is unaware of this outcome and who continues to patch corneal abrasions has an unrecognized information need, because his or her patients would benefit from a change in practice. When that same family physician asks this clinical question: "I wonder whether there is any evidence that patching corneal abrasions improves outcomes that my patients and I care about?" he or she has recognized an information need and asked a clinical question. When the physician asks a colleague, he or she has begun to pursue this information need. Searching the Fournal of Family Practice POEMs (patient-oriented evidence that matters) Web site (http:// www.infopoems.com) using the term "corneal abrasion" will locate an article that answers that clinical question; the information need is now satisfied. Finally, the information must be implemented in the physician's practice to affect patient outcomes.

This pathway is not linear. Rather, it is a cycle, because medical science is dynamic rather than static, and new information is constantly becoming available. Yesterday's satisfied and imple- 
mented information need is tomorrow's unrecognized need. For example, a new study has shown convincingly that topical nonsteroidal anti-inflammatory drops reduce pain and speed healing in corneal abrasion. ${ }^{10}$ If use of nonsteroidal antiinflammatory drugs was not the standard practice for this physician, the physician has an unrecognized need and begins the process anew.

In addition to the type of need, there are several other ways to classify physician information needs. Woolf and Benson ${ }^{5}$ describe several other characteristics of an information need: the type of information (eg, diagnostic, prognostic, therapeutic), the organ system, and the source of information used to answer the question. Osheroff et $\mathrm{l}^{8}$ describe the generalizability of an information need as whether it can be satisfied by generalizable sources of information, such as original research and the PDR, or whether the information need is specific to a particular patient. These different ways of classifying information needs (including clinical questions) are summarized in Table 1.

\section{Clinical Questions, Lifelong Learning, and Evidence-based Medicine}

While physicians are encouraged to practice lifelong learning, and continuing medical education is required by many organizations, it has not been successful at improving patient outcomes. ${ }^{11}$ Physician practice changes in haphazard ways, often not driven by the best available evidence. In fact, the best predictor of physician prescribing behavior regarding antihypertensive medications is the year of graduation from medical school! 12 Adult learning theory suggests that physicians will learn best when learning (1) is in the context of patient care, (2) answers their questions, (3) is directly applicable to their work, and (4) does not take too much time. ${ }^{13}$

Table 1. Ways to Classify Medical Information Needs.

\begin{tabular}{|c|c|c|}
\hline Axis & Components & Example \\
\hline \multirow[t]{5}{*}{ Type of need } & Unrecognized & Should have looked for drug interaction \\
\hline & Recognized & Thought about drug interaction, but did not pursue \\
\hline & Pursued & Looked for drug interaction information, but did not find it \\
\hline & Satisfied & Found information about a drug interaction \\
\hline & Implemented & Does not prescribe a medication because of the interaction \\
\hline \multirow[t]{8}{*}{ Type of information } & Etiology & Can Mycoplasma pneumoniae cause sore throat? \\
\hline & Differential diagnosis & What diagnoses should I consider in this patient with sore throat? \\
\hline & Clinical diagnosis & Is viral pharyngitis likely in a patient with exudate and adenopathy? \\
\hline & Laboratory diagnosis & $\begin{array}{l}\text { Is the rapid streptococcus screening test accurate enough to rule } \\
\text { out streptococcal pharyngitis, if negative? }\end{array}$ \\
\hline & Treatment & Is amoxicillin $500 \mathrm{mg}$ bid $\times 6 \mathrm{~d}$ as effective as $250 \mathrm{mg}$ tid $\times 10 \mathrm{~d}$ ? \\
\hline & Prognosis & If my patient is still symptomatic in 2 days, should I change therapy? \\
\hline & Patient education & What should I tell my patient about communicability? \\
\hline & Administrative & Does this patient's insurance pay the cost of antibiotics? \\
\hline \multirow[t]{4}{*}{ Organ-system } & Cardiovascular & What is the appropriate starting dose for enalapril in an 80 -year-old patient? \\
\hline & Pulmonary & When should I start inhaled steroids in an asthmatic patient? \\
\hline & Gastrointestinal & Is there a role for Helicobacter pylori eradication in nonulcer dyspepsia? \\
\hline & Etc & \\
\hline \multirow[t]{5}{*}{ Source of information } & Colleague & Asked one of my partners \\
\hline & Textbook & Consulted Harrison's Textbook of Internal Medicine \\
\hline & Original research & Referred to a recent article in Fournal of the American Medical Association \\
\hline & Online database & Did a MEDLNNE search \\
\hline & Other & \\
\hline \multirow[t]{2}{*}{ Generalizability } & Generalizable knowledge & What is the likelihood ratio for a CAGE alcohol screening score of 3 ? \\
\hline & Patient-specific question & What is this patient's most recent serum creatinine level? \\
\hline
\end{tabular}

CAGE - a mnemonic for trying to cut down on drinking, annoyance about criticism of drinking, guilt about drinking, and using alcohol as an eye-opener. 
Physicians who want to be successful lifelong learners therefore need highly developed critical reflection skills. Applying these skills to their practice and generating clinical questions at the point of care are central to physician education and lifelong learning. To take an evidence-based approach to practice, these questions must be answered using the most valid, relevant information available.

\section{Clinical Questions and Lifelong Learning}

The ideal evidence-based physician will critically reflect on his or her practice on a regular basis, asking whether there is a better way to do things. This physician will then answer the questions generated by this process of critical reflection using relevant, valid information, rather than anecdote or opinion, whenever possible. Finally, answers to questions that change the physician's practice will be implemented. Unfortunately, there are many potential barriers to this ideal model of reflective, evidence-based practice. These are summarized in Figure 1, along with the information pathway itself.

The first step in the information pathway is to recognize that an information need exists. The willingness to recognize that one's knowledge might not be complete would appear to be driven primarily by physician attitude and personality. Work by educators in the area of critical reflection suggests that this skill is mature and high-level, ${ }^{13}$ but that it might be undermined by an emphasis on what Argyris ${ }^{15}$ calls single-loop rather than double-loop learning. Consider the example of a patient who has a cough, which is diagnosed as bronchitis, and who is given erythromycin. When the patient returns 2 days later with persistent symptoms, the physician changes the antibiotic. This behavior is single-loop learning, because the physician reacts to the situation without questioning the underlying assumptions. A more reflective physician would practice double-loop learning: when the patient returns, both the underlying diagnosis and the treatment strategy are questioned. Maybe the patient does not have bronchitis. Perhaps the patient has reflux or allergies. What if the bronchitis is viral, and the antibiotic is not going to help anyway? Do antibiotics help even if the bronchitis is bacterial? The reflective physician, even in this simple clinical situation, generates a host of important questions.

In addition to generating more clinical ques- tions, the reflective physician is more likely to practice patient-centered medicine, tailoring the management strategy to the patient's clinical picture, needs, and situation. For example, taking a one-size-fits-all approach to the management of sore throat by ordering a rapid antigen test for everyone who has a sore throat provides too much care for some and not enough for others. By reflecting on practice and asking whether a rapid antigen test is needed for a particular patient, care is individualized and outcomes are perhaps improved.

Unfortunately, traditional medical education emphasizes knowing the right answer more than asking the right question. Too often, asking a question is punished by giving the busy intern or medical student the task of reporting the answer back to the group the next day! The traditional paternalistic view of physicians as all-knowing might make them afraid to admit that they do not know everything, and less likely to appraise critically their current practices. Such phrases as "This is the Michigan State (or Harvard, or Michigan, or Duke) way," and "We've always done it this way, and my patients do fine," further undermine our willingness and ability to critically reflect on our practices. Argyris has described similar defensive strategies in the business setting, and called them learned incompetence. Just as General Motors was slow to change its practices during the 1970 s and 1980s, physicians find many reasons to justify the status quo and resist positive change.

The decision to pursue a clinical question is perhaps the most complex step in the information pathway, influenced by physician attitude, personality, and work ethic; the characteristics of the question; and the practice environment. Previous research has shown that the decision to pursue a clinical question is driven most strongly by the importance of the question and the perceived availability of an answer to the question. ${ }^{7}$ The former might vary depending on physician characteristics such as conscientiousness, work ethic, and sense of duty to the practice. For example, one physician might believe that it is important to find out the best way to treat corneal abrasions, because the wrong decision might adversely effect some patients. Another, however. might be more complacent and believe that using a patch has always worked well enough.

The perceived availability of an answer to the 


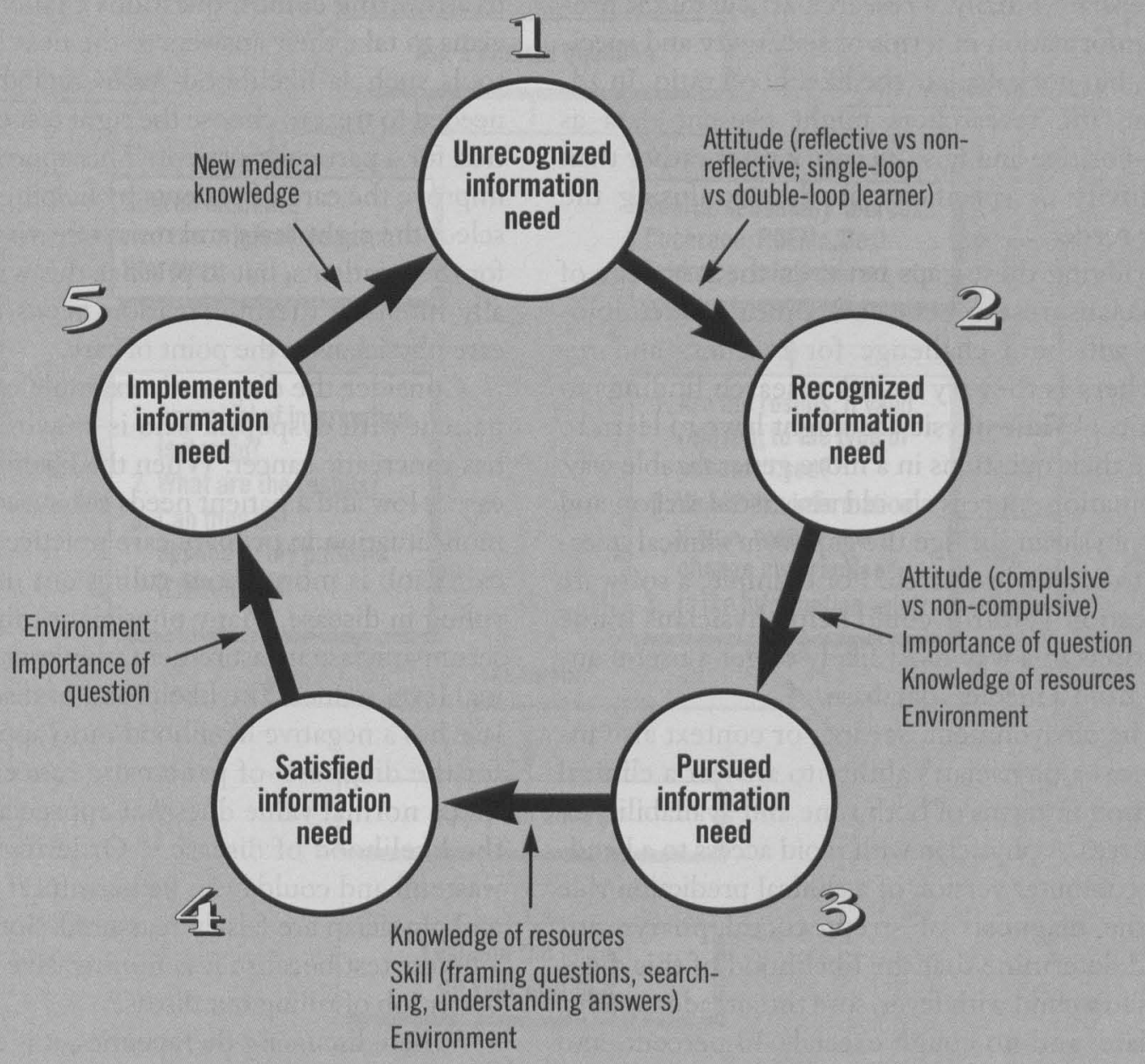

Figure 1. A model for information needs of physicians, showing the information pathway and key factors influencing each step.

question depends in part on the physician's knowledge of available resources. For example, a physician wondering about the efficacy of steroids in preterm labor might keep wondering because it would seem to be too difficult to find the answer. Knowing that the Cochrane Database of Systematic Reviews has many excellent systematic reviews on perinatal topics, however, might stimulate the physician to look there for an answer, especially if that physician had the necessary computer skills. Finally, environmental factors, such as access to information sources and the time available between patients, will affect the decision to pursue a clinical question. Having the Cochrane Database of Systematic Reviews abstracts on a handheld or office computer in the clinical area would eliminate a trip to the library and reduce the time needed to access the review.
The ability to satisfy an information need and answer a clinical question once the physician decides to pursue it is determined by the knowledge of available resources, skill at framing a question and searching these resources, and the context or environment. Physicians tend to frame questions in relation to specific patients 4,8 rather than in a generalizable fashion, as is advocated by teachers of evidence-based medicine. ${ }^{16}$ For example, a family physician might ask, "I have this 38-year-old patient with dyspepsia, whose father was diagnosed with pancreatic cancer. He's really worried that he has pancreatic cancer, and I want to reassure him. What is the best test to rule out pancreatic cancer for him? Should I order a sonogram?" A clinical epidemiologist or evidence-based medicine proponent might frame this question as, "What is the test with the best negative likelihood ratio for pan- 
creatic cancer among outpatients like this with dyspepsia?" Finally, a research article might provide information in terms of sensitivity and specificity, but not calculate the likelihood ratio. In addition, the researchers might present data as false-positive and false-negative rates rather than sensitivity or specificity, further confusing the naive reader.

Bridging these gaps between the language of physicians, researchers, and clinical epidemiologists will be a challenge for teachers and researchers as they try to link research findings to practice. While physicians might have to learn to frame their questions in a more generalizable way, information sources should also avoid jargon and help physicians bridge the gap from clinical question to original research. For example, a software "Question Wizard" could help physicians frame questions in a way most likely to get a useful answer from a medical database.

The environment, setting, or context also influences a physician's ability to answer a clinical question in terms of both time and availability of resources. A physician with rapid access to a handheld computer version of a clinical prediction rule for the diagnosis of streptococcal pharyngitis could determine that the likelihood of this diagnosis in a child with fever, sore throat, adenopathy, exudate, and no cough exceeds 40 percent, and empiric treatment is appropriate. Without that clinical prediction rule in a rapidly available format, the physician might order a rapid antigen test and be misled by a false-negative test result.

Finally, the decision to implement the answer to a clinical question in practice will depend on such environmental factors as cost, health system constraints, patient acceptance, acceptance of colleagues, and local practice patterns. The amount of work needed to implement a change as well as the importance of the question are both important. For example, it is easy to stop patching corneal abrasions but very difficult to establish a stroke unit in a local hospital. Nevertheless, if the outcomes are important enough in terms of reduced morbidity and mortality, then it should be worth the effort to establish such a unit.

\section{Information Needs and Evidence-based Medicine}

An evidence-based approach to care can be information intensive. It challenges the physician to know not only the "what" of care, but the "how much" as well. Taking an evidence-based approach $\frac{c}{3}$ to answering clinical questions challenges physicians to take their answers to the next level, using $\frac{0}{2}$ tools such as likelihood ratios and the number T needed to treat to choose the right test or interven- 3 tion for a particular patient. This approach should $\frac{T}{0}$ improve the care of patients by helping physicians $\stackrel{?}{?}$ select the right tests and most effective therapies $\underset{\Rightarrow}{\stackrel{F}{\rightarrow}}$ for their patients, but to practice this way can actually intensify the information needs of primary care physicians at the point of care.

Consider the diagnostic example of a worried patient with dyspepsia who is convinced that he $\overrightarrow{0}$ has pancreatic cancer. When the likelihood of dis- $\dot{\omega}$ ease is low and a patient needs reassurance, a common situation in primary care practice, the physician's job is more about ruling out disease than ruling in disease. Many physicians might order a $\underset{\omega}{\vec{N}}$ serum amylase measurement, thinking that a normal level reduces the likelihood of disease. Amy-

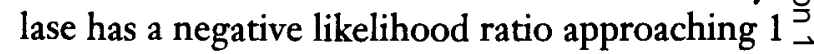
for the diagnosis of pancreatic cancer, meaning that a normal value does not appreciably reduce the likelihood of disease. ${ }^{18}$ Ordering the test is wasteful and could even be harmful if the patient and physician are falsely reassured. Sonography is a better test because it is noninvasive and does a better job of ruling out disease.

When discussing therapeutics, it is common to $\stackrel{\circ}{\Rightarrow}$ think in terms of risk reduction. For example, how $\frac{\overline{3}}{3}$ much does pravastatin (Pravachol) reduce the risk of death in men at high risk of developing heart disease? A recent study ${ }^{19}$ showed that during a 5 year period use of pravastatin decreased the allcause mortality rate from 4.1 percent to 3.2 percent, a 22 percent relative risk reduction ([4.1 $3.2] / 4.1=22$ percent $)$. The absolute risk reduction, however, is only 0.9 percent $(4.1-3.2=0.9$ percent). Clearly, this number is less impressive than the 22 percent relative risk reduction, even though the underlying data have not changed. An even $N$ more clinically meaningful way of describing the $\stackrel{N}{\omega}$ benefits of treatment uses the number needed to treat. Dividing the absolute risk reduction of $0.9 \stackrel{\circ}{\stackrel{\odot}{\Phi}}$ percent into 100 , one finds that 110 adults at high $\stackrel{?}{?}$ risk of developing heart disease would have to take ${ }^{\circ}$ pravastatin for 5 years to prevent one death. This information can help physicians and patients put $\stackrel{\vec{D}}{\stackrel{2}{2}}$ the costs, risks, and benefits of cholesterol-lowering therapy into perspective.

In conclusion, to become reflective, evidence- 


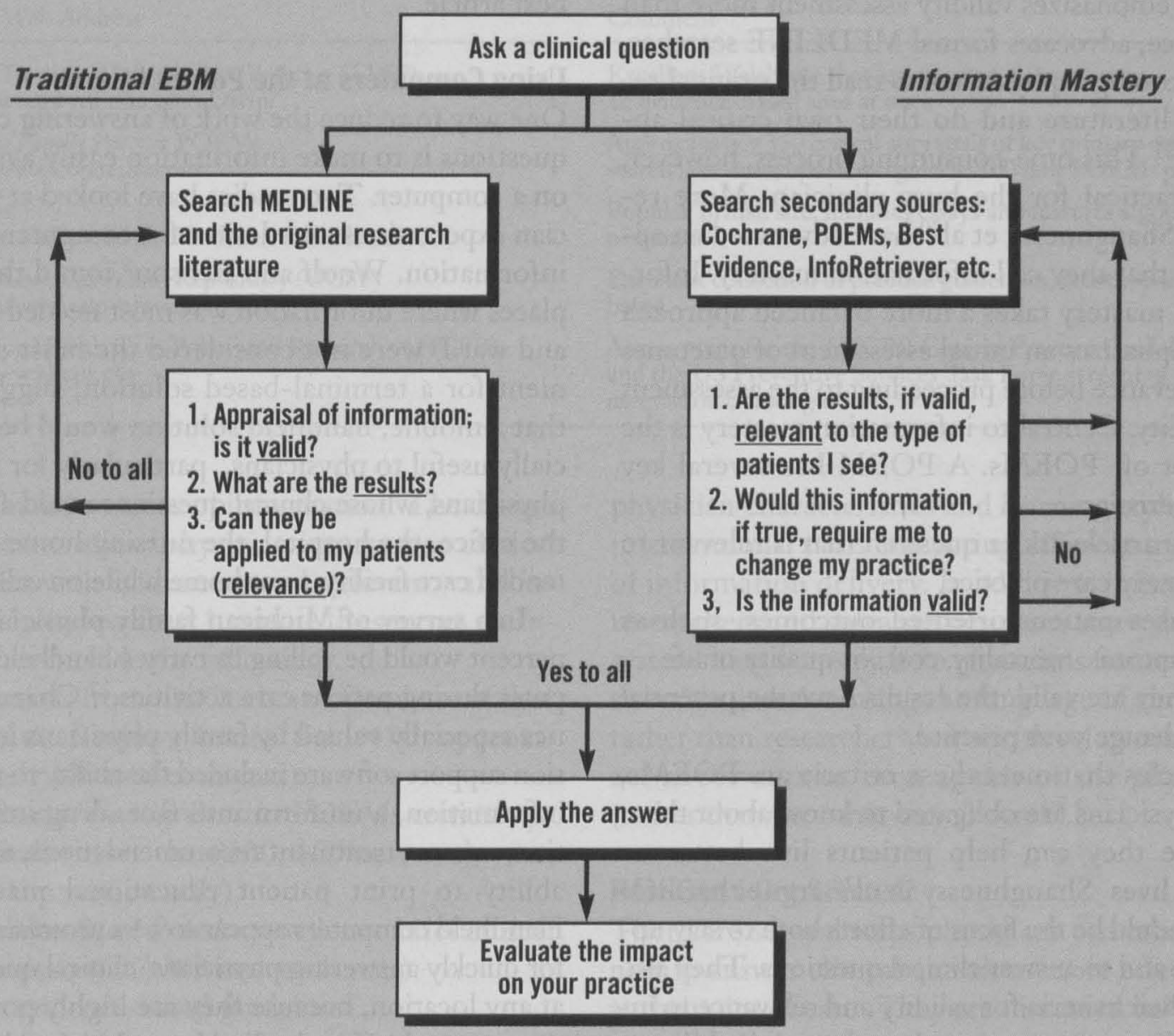

Figure 2. Traditional evidence-based medicine (left path) and information mastery (right path). Note that information mastery offers a more efficient approach to implementing an evidence-based approach to patient care, because it emphasizes use of predigested sources of information and brief relevance screening before a more lengthy validity evaluation.

based practitioners, it is important that physicians (1) critically reflect on their practice, using double-loop learning that questions underlying assumptions about care; (2) value the questions; (3) have the skills, time, and resources to answer questions using evidence-based sources of information; and (4) be able to implement the answers to questions in the care of patients

\section{How Can Physicians Answer Clinical Questions at the Point of Care? \\ Information Mastery Instead of Evidence-based Medicine}

Richard Smith, editor of the British Medical fournal, states: "New information tools are needed: they are likely to be electronic, portable, fast, easy to use, connected to both a large valid database of medical knowledge and the patient record, and a servant of the patient as well as doctors." 4 Shaughnessy and colleague ${ }^{20}$ have described the usefulness of medical information as follows:

$$
\begin{aligned}
& \text { Usefulness of } \\
& \text { information }
\end{aligned}=\frac{\text { Relevance } \times \text { Validity }}{\text { Work }}
$$

Thus, the most useful information is relevant to a practice, highly valid, and takes very little work to acquire. This insight can guide in defining and even designing resources for answering clinical questions at the point of care.

The traditional approach to evidence-based medicine teaches a five-step approach: question, 
search, appraise, apply, and evaluate. This approach emphasizes validity assessment more than relevance, advocates formal MEDLINE searches, and encourages physicians to read the original research literature and do their own critical appraisal. ${ }^{21}$ This time-consuming process, however, is impractical for the busy clinician. More recently, Shaughnessy et al ${ }^{20}$ have advocated an approach that they call information mastery. Information mastery takes a more balanced approach and emphasizes an initial assessment of outcomes and relevance before proceeding to the assessment of validity. Central to information mastery is the concept of POEMs. A POEM has several key characteristics:

1. The article asks a question that is relevant to primary care practice.

2. It uses patient-oriented outcomes, such as symptoms, mortality, cost, or quality of life.

3. If they are valid, the results have the potential to change your practice.

Articles that meet these criteria are POEMs, and physicians are obligated to know about them because they can help patients live better or longer lives. Shaughnessy et $\mathrm{al}^{20}$ argue that POEMs should be the focus of efforts both to stay upto-date and to answer clinical questions. They also apply their criteria for validity and relevance to information sources other than the original literature, and they emphasize use of secondary sources of literature such as Evidence-Based Practice, Evidence-Based Medicine, Fournal of Family Practice POEMs, and the American College of Physicians (ACP) Journal Club.

The difference between traditional evidencebased medicine and information mastery is shown graphically in Figure 2. Whereas the traditional approach remains the basis for those who perform meta-analyses, systematic reviews, and critical appraisals for secondary literature journals, information mastery provides a much more accessible and efficient way for physicians to keep up-to-date and answer their clinical questions rapidly at the point of care. For example, it is much easier to search the Cochrane Library, Best Evidence, or InfoRetriever CD-ROMs than all of MEDLINE. Also, rather than beginning with a time-consuming validity assessment, Shaughnessy et $\mathrm{al}^{20}$ advocate reading the abstract to find out whether the outcomes are patient-oriented and whether the conclusion recommends a change to your current practice. If ei- ther answer is no, you can stop and move on to the $\frac{\text { s }}{3}$ next article.

\section{Using Computers at the Point of Care}

One way to reduce the work of answering clinical 3 questions is to make information easily available on a computer. Two studies have looked at physi-? ? cian expectations and desires for computer-based $\overrightarrow{\vec{\sigma}}$ information. Woolf and Benson ${ }^{5}$ found that the places where information was most needed (clinic $\frac{\overline{\bar{N}}}{\overline{\mathrm{s}}}$ and ward) were not considered the most conve- $-\widehat{\Phi}$ nient for a terminal-based solution, suggesting that a mobile, handheld solution would be espe- $\vec{\circ}$ cially useful to physicians, particularly for family physicians, whose clinical questions could arise in

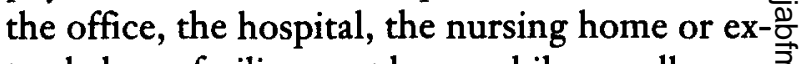
tended care facility, or at home while on call.

In a survey of Michigan family physicians, $85 \stackrel{\vec{\omega}}{\vec{\omega}}$ percent would be willing to carry a handheld com- $N$ puter during patient care activities. ${ }^{22}$ Characteris- $-\circ$ tics especially valued by family physicians in decision support software included the ability to update information, a uniform interface, drug information, current treatment recommendations, and the ability to print patient educational materials. Handheld computers appear to be a promising tool for quickly answering physicians' clinical questions at any location, because they are highly portable, $\frac{\mathscr{Q}}{\varnothing}$ turn on and off immediately, and have adequate $\underset{\vec{P}}{\stackrel{\Omega}{\vec{p}}}$ memory and speed for the task of medical informa- $\frac{0}{3}$ tion management and reference. ${ }^{23}$ Eventually these units will provide inexpensive, continuous, wireless connections to the Internet and local area networks. A previous article described handheld com puters and software for physicians. ${ }^{23}$

Many physicians now have computers at or near the point of care. Excellent sources of evidence-based information for desktop computers include the Cochrane Library (http://www.update- $\rightarrow$ software. com/ccweb/cochrane/cdsr.htm) from? the Cochrane Collaboration and the Best Evidence ${ }_{0}$ reference from the American College of Physi- $\mathrm{\omega}$ cians and the British Medical fournal Publishing Group (http://www. acponline.org). Both the Cocbrane Library and Best Evidence are available on? CD-ROM. Useful Web sites for answering clini-ō cal questions using evidence-based information are shown in Table 2.

InfoRetriever, a handheld software program developed by Ebell and Barry at Michigan Stateo University, ${ }^{24}$ brings together a variety of evi- 
Table 2. Web-based Sources of Evidence-based Clinical Information.

\begin{tabular}{|c|c|}
\hline Site and Web Address & Comment \\
\hline $\begin{array}{l}\text { Gwent/ Turning Research Into Practice (TRIP) } \\
\text { http://www.gwent.nhs.gov.uk/trip/ }\end{array}$ & $\begin{array}{l}\text { Excellent Welsh site that lets you search more than } \\
12 \text { evidence-based sites at once }\end{array}$ \\
\hline $\begin{array}{l}\text { Fourmal of Family Practice POEMs } \\
\text { http://www.infopoems.com }\end{array}$ & $\begin{array}{l}\text { Approximately } 350 \text { critical appraisals of key primary care re- } \\
\text { search literature; updated regularly, } 100 \text { new POEMs per year }\end{array}$ \\
\hline $\begin{array}{l}\text { Bandolier } \\
\text { http://www.jr2.ox.ac.uk/Bandolier/index.html }\end{array}$ & $\begin{array}{l}\text { Popular British site, includes essays and features a good sense } \\
\text { of humor }\end{array}$ \\
\hline $\begin{array}{l}\text { Primary Care Guideline Repository (UCSF) } \\
\text { http://itsa.ucsf.edu-petsam// }\end{array}$ & $\begin{array}{l}\text { Excellent collection of practice guidelines, mostly evidence- } \\
\text { based }\end{array}$ \\
\hline $\begin{array}{l}\text { Agency for Health Care Policy and Research (AHCPR) } \\
\text { http://www.ahcpr.gov }\end{array}$ & $\begin{array}{l}\text { Access point for the AHCPR Clinical Practice Guidelines } \\
\text { and the US Preventive Services Task Force screening recom } \\
\text { mendations, among others }\end{array}$ \\
\hline
\end{tabular}

dence-based sources of information. The design goal was to allow physicians to answer clinical questions with evidence-based, relevant, valid information in less than 1 minute. Resources on InfoRetriever include the following:

1. Abstracts from the Cochrane Database of Systematic Reviews (more than 470; approximately 100 new each year)

2. Fournal of Family Practice POEMs critical appraisals (more than 300; 100 new each year, desktop version only)

3. Evidence-Based Practice newsletter brief critical appraisals $(600 ; 300$ new each year)

4. Key evidence-based guidelines

5. Detailed history, physical examination, and diagnostic test information integrated in a calculator for interpreting results

6. Validated clinical prediction rules

7. Drug information

The software was originally written for the Newton series of handheld computers (now discontinued) and is being moved to the Windows 95, Windows NT, and Windows CE operating systems for desktop and handheld computers (http://www.infopoems.com). Studies to evaluate the impact of InfoRetriever on student learning, physician behavior, and a physician's ability to answer questions are underway.

Certainly more research is needed into the information needs of primary care physicians. First, clinical questions in a variety of settings must be collected and classified, creating a taxonomy of information needs. Other studies will include comparisons of different types of physicians who might have different needs, ${ }^{5,7}$ a focus on the effect of interventions on both patient outcomes and information-seeking behavior, ${ }^{7}$ studies that consider physician characteristics and learning styles, and interventional trials comparing different methods of information delivery. In addition, informatics researchers and software designers must develop systems that not only help physicians frame an answerable question using the language of clinicians rather than researchers but also develop tools that act as servants or even agents of the physician (rather than the other way around!). ${ }^{5}$

\section{How Can I Get Started?}

There are several steps physicians can take right now to answer clinical questions more effectively at the point of care. They are discussed below.

\section{Reflect on Your Practice on a Regular Basts}

Medical students, residents, and practitioners build an extensive database of clinical experience and medical knowledge. Like any database, though, it can grow out-of-date. Regularly reflecting on decisions and practices will stimulate clinical questions. Answering these clinical questions using valid, relevant information will keep a database up-to-date. A simple method is to keep an index card in a pocket and write down questions that cannot be answered immediately. Then, make a commitment to answer at least one or two of the most compelling questions each week.

\section{Inquire, Don't Advocate}

Too often, physicians advocate a plan for a patient or a belief about a condition rather than inquire into the best possible approach for the patient(s). Advocacy is prefaced by such statements as "I think ...," "I believe ...," "The facts are ...," "Experience says ....," and "My colleagues always ...." 
Inquiry, on the other hand, is characterized by such statements as, "What do you think?" "I wonder whether there is a better way?" "Should I keep doing this?" and "Why have I always ...?" When you find yourself making advocacy statements, ask yourself whether you could instead inquire. Whereas advocacy tends to uphold the status quo, inquiry leads to new knowledge and new insights.

\section{Feel Good About Not Knowing Everything}

It is impossible for any physician, especially a primary care physician, to know everything. Family practice is a specialty defined in breadth rather than depth. ${ }^{25}$ Reading should therefore focus on problems common or important to your patients. When you find an article about such a problem, make sure it uses outcomes that matter to your patients, such as symptom improvement, mortality reduction, cost, or quality of life. An article that is valid and would change your practice is a POEM. Fortunately, only approximately 2 percent of the medical literature is POEMs (Henry Barry, personal communication, May 1999), so this approach will help get rid of the stack of unread journals. Because the findings of a POEM have been shown to improve important patient outcomes and because they differ from your current practice, Shaughnessy et $\mathrm{al}^{20}$ argue that you are ethically obligated to know about POEMs and apply them to your practice. To learn more about POEMs, see the Fournal of Family Practice Web site at http://www.infopoems.com.

\section{Learn to Ask a Focused Clinical Question}

Too often clinical questions are couched in terms specific to a particular patient. Asking "What test should I order for this 28-year-old woman with chest pain?" is appropriate when talking to a human consultant but not when searching a medical reference. Instead, asking "What is the best test to rule out myocardial infarction in this person with chest pain and a low likelihood of disease?" is more likely to lead you to the information you need to make a decision. David Sackett and colleagues ${ }^{16}$ have written an excellent chapter on this topic in their book Evidence-Based Medicine: How to Practice and Teach EBM'.

\section{Let Someone Else Do the Heavy Lifting}

There are now several excellent sources of what is called secondary literature. Each has a group of physicians trained in critical appraisal, epidemi ology, and research design who select importang articles, critically appraise them for validity, an publish the results in brief synopses.

Examples include the ACP Journal Club Fournal of Family Practice POEMs feature, Evi dence-Based Practice newsletter, and the journa?: Evidence-Based Medicine. By distilling a mountair? of medical literature to the most important $10 \mathrm{o}$ 응 20 pages every month, these resources make $i \frac{5}{\bar{n}}$ possible for physicians to remain up-to-dat without spending inordinate amounts of time in the library.

\section{Learn To Use a Computer}

The best evidence-based sources of answers tơ clinical questions are available on computers, and there is a growing list of highly useful World Wide Web sites (Table 2). In addition, it is possi 점 ble to search the MEDLINE database of the Nao tional Library of Medicine for free via the Web-

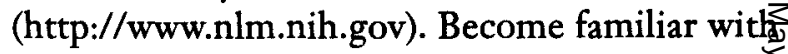
excellent evidence-based sources of information such as the Cocbrane Library, Best Evidence, and In 6 foRetriever programs. They should be your firs stop for answers to clinical questions. Better yets consider purchasing a handheld computer. Hand held computers can go where you go and help an swer clinical questions at the bedside, in the of $\overrightarrow{\vec{*}}$ fice, in the elevator, at home, or wherever they arise.

Only by being critically reflective practitioners will family physicians improve their practice ans the health of their patients. This style of practice is not only good for patients, it is intellectuall stimulating, and can help primary care physiciane successfully address a wide variety of problems with greater confidence.

Be patient toward all that is unsolved in your beart an try to love the questions themselves like locked roomis and like books that are written in a very foreigy tongue... Live the questions now. Perbaps you will the gradually, without noticing it, live along some distan day into the answer.

- Rainer Maria Rilke

Drs. David Rovner, Margaret Holmes-Rovner, Henry Barry David Slawson, Allen Shaughnessy, Charles Given, and Laurß Bierema provided thoughtful, critical review of this work an made many useful suggestions. 


\section{References}

1. Hersh WR, Lunin LF. Introduction and overview [special issue on medical informatics]. J Am Soc Inform Sci 1995;46:726-8.

2. Barrie AR, Ward AM. Questioning behaviour in general practice: a pragmatic study. BMJ 1997;315: 1512-5.

3. Covell DG, Uman GC, Manning PR. Information needs in office practice: are they being met? Ann Intern Med 1985;103:596-9.

4. Smith R. What clinical information do doctors need? BMJ 1996;313:1062-8.

5. Woolf S, Benson DA. The medical information needs of internists and pediatricians at an academic medical center. Bull Med Libr Assoc 1989;77:37280.

6. Gorman PN, Ash J, Wykoff L. Can primary care physicians' questions be answered using the medical journal literature? Bull Med Libr Assoc 1994;82: 140-6.

7. Gorman PN, Helfand M. Information seeking in primary care: how physicians choose which clinical questions to pursue and which to leave unanswered. Med Decis Making 1995;15:113-9.

8. Osheroff JA, Forsythe DE, Buchanan BG, Bankowitz RA, Blumenfeld BH, Miller RA. Physicians' information needs: analysis of questions posed during clinical teaching. Ann Intern Med 1991;114:576-81.

9. Kaiser PK. A comparison of pressure patching versus no patching for corneal abrasions due to trauma or foreign body removal. Corneal Abrasion Patching Study Group. Ophthalmology 1995;102:1936-42.

10. Kaiser PK, Pineda R 2 nd. A study of topical nonsteroidal anti-inflammatory drops and no pressure patching in the treatment of corneal abrasions. Corneal Abrasion Patching Study Group. Ophthalmology 1997;104:1353-9.

11. Davis DA, Thomson MA, Oxman AD, Haynes RB. Changing physician performance. A systematic review of the effect of continuing medical education strategies. JAMA 1995;274:700-5.

12. Evans CE, Haynes RB, Birkett NJ, Gilbert JR, Taylor DW, Sackett DL, et al. Does a mailed continuing education program improve physician performance? Results of a randomized trial in antihypertensive care. JAMA 1986;255:501-4.
13. Knowles MS. Self-directed learning: a guide for learners and teachers. Chicago: Association Press, 1975.

14. Mezirow $\mathrm{J}$ and associates. Fostering critical reflection in adulthood: a guide to transformative and emancipatory learning. San Francisco: Jossey-Bass, 1990.

15. Argyris $C$. Reasoning, learning, and action: individual and organizational. San Francisco: Jossey-Bass, 1982.

16. Sackett DL, Richardson WS, Rosenberg W, Haynes RB. Evidence-based medicine: how to practice and teach EBM. New York: Churchill Livingstone, 1997.

17. Geyman JP. Evidence-based medicine in primary care: an overview. J Am Board Fam Pract 1998;11: 46-56.

18. Fitzgerald PJ, Fortner JG, Watson RC, Schwartz MK, Sherlock P, Benua RS, et al. The value of diagnostic aids in detecting pancreatic cancer. 1978;41: 868-79.

19. Shepherd J, Cobbe SM, Ford I, Isles CG, Lorimer AR, MacFarlane PW, et al. Prevention of coronary heart disease with pravastatin in men with hypercholesterolemia. West of Scotland Coronary Primary Prevention Study Group. N Engl J Med 1995;333: 1301-7.

20. Shaughnessy AF, Slawson DC, Bennett JH. Becoming an information master: a guidebook to the medical information jungle. J Fam Pract 1994;39:489-99.

21. Oxman AD, Sackett DL, Guyatt GH. Users' guides to the medical literature. I. How to get started. The Evidence-Based Medicine Working Group. JAMA 1993;270:2093-5.

22. Ebell MH, Gaspar DL, Khurana S. Family physicians' preferences for computerized decision-support hardware and software. J Fam Pract 1997;45: $137-41$

23. Ebell MH, Hale W, Buchanan JE, Dake P. Handheld computers for family physicians. J Fam Pract 1995;41:385-92.

24. Ebell $\mathrm{MH}$, Barry HB. InfoRetriever: bringing evidence-based information to the point of care. MD Computing 1998; [published?].

25. McWhinney IR. A textbook of family medicine, 2nd ed. New York: Oxford University Press, 1997. 